\title{
Multi-Agent Simulation Applied to On-Line Music Distribution Market
}

\author{
Maite López-Sánchez, \\ MAiA Dept. \\ University of Barcelona \\ maite@maia.ub.es
}

\author{
Xavier Noria, \\ iSOCO, Intelligent \\ Software Components \\ fxn@isoco.com
}

\author{
Juan A. Rodríguez, \\ IIIA, Inst. Investigació \\ Intel·ligència Artificial \\ jar@iiia.csic.es
}

\author{
N. Gilbert, S. Schuster \\ University of Surrey \\ (n.gilbert,s.schuster)@ \\ @ soc.surrey.ac.uk
}

\begin{abstract}
Over the past few years it has become clear that the Internet will play an ever greater role in the distribution of digital contents. Our main aim is to provide businesses in the digital contents sector with a tool which will enable them to take informed business strategy decisions and become more competitive by adapting their traditional business models to the new, demanding reality. To achieve this objective, we have implemented a first version of a music market model called Simweb $A^{+}$that is based on multi-agent simulation technology. In our simulations, agents represent market stakeholders that act autonomously according to their interests and interact with other agents inside the market environment. This allows end users to investigate the implications of a variety of decisions and strategies by running simulations starting from different initial conditions.
\end{abstract}

\section{Introduction}

Digital content distribution is changing rapidly due to the emergence and spread of new business models and technologies. Specialised portable hardware, designed to store and give digital access to contents such as news, books, music, or video, will soon make digital contents reachable by a large number of consumers. To achieve success, e-businesses are being forced to rethink traditional, strategic business models, the role of IT (information technology), processes and relationships along the whole length of the supply chain ([2]). This is because, as Wurman ([9]) argues, with the advent of ecommerce, the marketplace as traditionally understood (in the 'town square') has become more global and to a greater extent more virtual. Businesses need to understand the dynamics of this new market and gain insight into how to exploit the impending paradigm shift in content, marketing, and distribution.

\footnotetext{
${ }^{\dagger}$ The work on which the paper is based has been conducted as part of a European Union supported project, contract IST2001-34651: Simweb (http://www.simdigital.com/).
}

Our main aim is to provide businesses in the digital contents sector with a tool which will help them to take informed business strategy decisions and, therefore, to become more competitive by adapting their traditional business models to the new marketplace. At this aim, we have implemented SimwebA, a first version of a music market model that is based on multi-agent simulation and market data extracted both from extensive sector surveys ([3]) and from close interaction with real content providers. SimwebA allows market participants in the digital contents sector to run a variety of scenarios and observe the impact they have both on their businesses and on the competitive digital contents landscape. The insights gained during these simulation runs provide them with a better understanding of the hitherto unexplored dynamics of the market, and permit them to adjust their own business models to the new competitive demands.

Multi-agent based simulation (MABS) ([4]) uses models that incorporate agents, where agents are understood as autonomous computer programs (or parts of programs) that are goal-directed and interactive and that are located in, and react to their simulated social and physical environment ([8]). In our simulations, agents represent market stakeholders that act autonomously according to their interests and interact with other agents inside the market environment. This allows end users to investigate the implications of a variety of decisions and strategies by running simulations starting from different initial conditions. Simulation results can be then analysed, either intuitively or through a statistical analysis, and this (together with flexibility) provides one of the main advantages of this MABS approach.

\section{Market model}

We have focused on modelling the structure and behaviour of the on-line music $\mathrm{B} 2 \mathrm{C}$ market and their constituents or stakeholders. The model consists of a population of content providers and customers that mainly interact by buying and selling products. Providers are retailers and buyers represent population segments. SimwebA is an ongoing project, and in due course we 
shall extend the model to include a larger number of stakeholder categories and interactions, a more sophisticated range of stakeholder actions and the possibility of agent learning.

Using SimwebA, the user can create markets, and for each market (which acts as the environment), define as many products, providers and customers as required:

- Every product (see Figure 1) is characterised by its own features (attributes that take values based on the type domain chosen by the user). Product offers and requests are central to the model, since they define what is being traded in the market.

- Provider agents offer products under certain conditions (e.g. subscription period) and interact with customers by advertising and selling these product offers.

- Customer agents reach their goals by buying product offers that best satisfy their preferences.

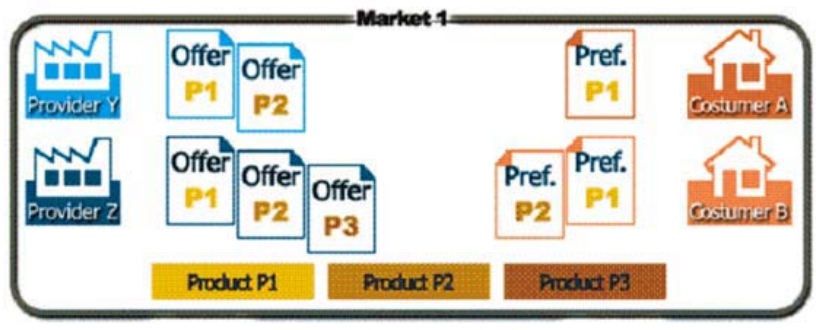

Figure 1. Main components in the market model

\subsection{Products}

Products represent goods traded in the market, and can be defined by sets of features such as size or price. In SimwebA, products are generic descriptions specified as sets of attributes, each of them having a name, a type and, when required, a set of possible values.

Our music model defines different products: Temporary Download; Full Length Streaming; Permanent Download and Burning. Figure 2 illustrates our 'Full Length Streaming' product definition. Other products have additional attributes ('Transfers to Portable Devices', 'Number of Burnings', etc.). Obviously, both products and attributes depend on the market it is being modelled.

\section{Product: Full Length Streaming}

- Price: Numerical interval [0, 3]. Prices must be comprised between 0 (meaning free) and 3 . Values are normalised to price per 1 song. Units are euros ( ).

- Bitrate: Numerical values.

- Type of Content: Set of \{"Back Catalog", "New Release", "Premium"\} label values.

- Codecs: Set of \{"WMA", "Real Audio", "AAC"\}

Figure 2. Full Length Streaming product definition

\subsection{Requests and Offers}

Providers can offer a product with different conditions, and thus they can generate any number of offers by assigning different attribute values to one product. Nevertheless, customers not only buy products because of their specific features, but also because of the characteristics of the provider itself. Therefore, SimwebA allows to add a set of provider attributes to each offer analogously to product attributes (see Figure 3).

Analogously to offers, requests (see Figure 3) allow customers to define desired values for each attribute in the offer definition. Customer agents state their preferences as either a single value or a range of preferred values. In the latter case, all values in the range are desirable, although customers can establish slopes for the preferences. In this manner, a FLAT preference means all values are equally preferred; MIB (More is Better) indicates higher values are preferred to lower ones; whereas LIB (Less Is Better) states the opposite. Additionally, when customer agents specify their preferences for product attributes, they also need to provide a weight value per attribute, which signals the importance the customer gives to that attribute.

By default, SimwebA assumes requested values are preferred but not mandatory (customers can define mandatory attributes). Therefore, a customer will still consider an offer not perfectly fulfilling all its requirements. In our model, mandatory attributes are very useful for attributes such as 'Codecs' because if, for example, a customer can only reproduce 'Real Audio", then a very good offer in WMA is of no value.

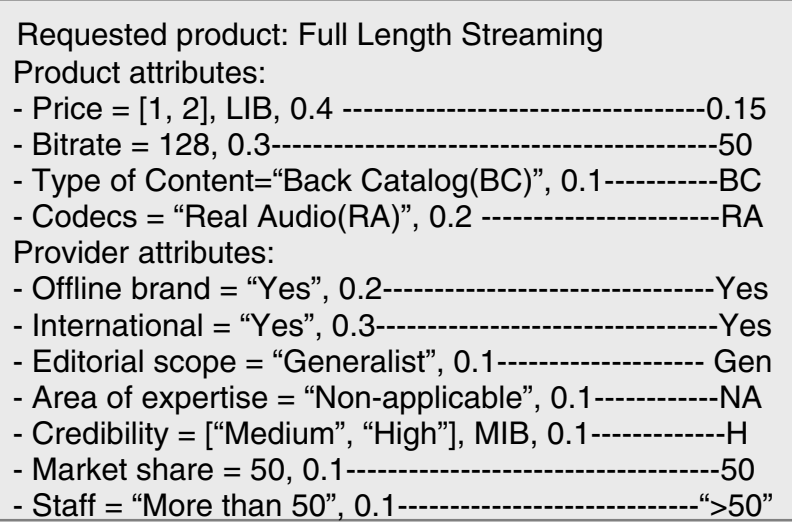

Figure 3. Example of a request for Full Length Streaming. Due to the lack of space, on the right side we include the offered values for a Full Length Streaming offer example.

\subsection{Matching Requests and Offers}

When buying, customers do always look for offers that satisfy their necessities. SimwebA computes satisfaction by matching requests and offers. Matching degrees are 
computed with iSOCO's fuzzy matching engine iMatcher, which scores and ranks each offer according to the customer's preferences (see [7] for details). Each attribute preference in an offer is internally represented as a satisfaction function, which corresponds to the membership function of the fuzzy set [5] defined by the preference. $\mathrm{X}$ axes on these functions correspond to attribute domains (types in product definitions) and $\mathrm{Y}$ axes are satisfaction degrees normalized to 1 . Y values are assigned based on preferred values and slopes.

As an example, figure 4 shows the satisfaction function for the Price attribute: most preferred value $(1 €)$ gets maximum satisfaction (that is, 1); last preferred value ( $2 €)$ gets a satisfaction degree of 0.5 ; and values outside the preferred range get satisfaction degrees that decrease proportionally down to 0 so that offered values that do not match preferences exactly still get positive satisfaction.

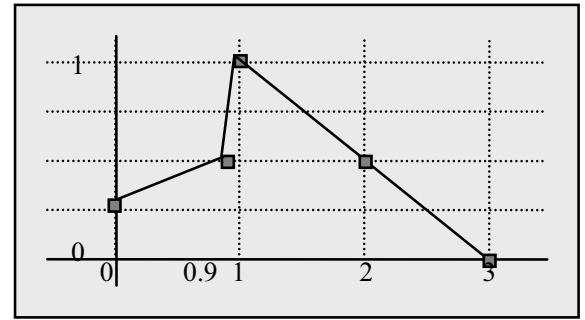

Figure 4. Satisfaction function for the Price attribute. $S(1)=1, S(2)=S(0.9)=0.5, S(0)=0.275, S(3)=0$

Values outside flat intervals decrease proportionally with the distance to the preferred values on both sides of the interval. For example, if the preferred value is 'Medium', both 'Low' and 'High' offered values should take the same satisfaction degree. On the contrary, symmetry does not apply for non-Flat preference intervals: satisfaction degrees for offered values falling on the left side outside an LIB interval decrease with a slope twice smother than right-sided values (and it is analogous for MIB intervals). Following the example in Figure 5, satisfaction values for prices between 2 and 3 decrease with a slope of -0.5 , whereas prices in $[0,0.9]$ increase their satisfaction with a slope of 0.25 . Therefore, if a 'Full Length Streaming' product is offered for free, the price attribute will take a satisfaction degree of 0,275 . Considering the offer shown in figure 3 , the $0.15 €$ price value will result in a satisfaction degree of 0.3125 .

Finally, once attribute satisfaction degrees have been computed for every attribute, overall matching degrees are afterwards computed as a weighted mean of individual attribute satisfaction degrees. This weighted mean uses the weights the customer has specified for each attribute in its request.

\section{Customer and Provider Agents}

The on-line music market includes a variety of stakeholders: artists, label/record companies, music portals, telco/PTTs, Internet service providers, payment system providers, and technology providers. Nevertheless, our current implementation focuses on music distribution companies (that comprises recording industry, and on-line retailers including music portals), and we have modelled some generic provider agents that correspond to real players in the on-line news market such as Sony or Fnac.fr.

In order to sell a product, every provider agent must advertise their offers, so that customer agents are aware of what is on the market when choosing the one to buy. Customers are modelled without the ability to remember advertisements and so providers must keep advertising their offers at each step in the simulation. Currently, advertising is done to all customers in the market (without segmentation), and provider agents sell products as soon as there are customer agents willing to buy them (do not favour customer aggregated demands nor apply customer loyalty policies). Additionally, provider agents just keep information (about deals, advertisements and "products in fashion") for displaying purposes, but we plan to apply it in marketing policies in future implementations. Furthermore, we are currently developing more complex provider behaviours by adding behaviour rules.

Since our market models an online B2C music market, we have defined customer agents representing end consumer segments. They buy songs from music providers for individual usage and not for further public distribution. We have distinguished two major endconsumer segments: "Early adopters" and "Ordinary Music Buyers". In general, "Early adopters" are willing to pay higher prices for those music products of "New Release" type of contents, whereas ordinary music buyers will tend to prefer low prices. We have defined and implemented five buying behaviours.

Buy Best offers behaviour. This behaviour models the "rational" customer and tries to satisfy its own request as much as possible. In order to do this, it first computes the matching degree of each request against all providers' offers for the same product, and then chooses the best one provided that it is satisfying enough (we have set a 0.7 threshold). Matching degrees are computed as explained in subsection 2.4.

Buy Cheapest offers behaviour. This behaviour models "bargain hunter" customers. Customer agents with this behaviour use requests to look for products to buy but do not consider attribute preferences, since they simply choose the offer with lowest price

Be Loyal to Provider behaviour. Although rational, some customers have such strong preferences for specific 
providers that they always buy from them. The implementation of this behaviour requires the specification of the provider to be loyal, and then it uses the request to see which offers from this provider fit best.

Follow Fashion behaviour. Some other customers decide to buy fashionable products. Fashion is modelled in terms of market sales, and hence the product in fashion is the top selling product.

Satisfy Requests Exactly behaviour. This final type of behaviour models customers that are extremely demanding, so that their requests must be satisfied exactly. This behaviour has been implemented by treating all attributes in the request as mandatory.

\section{Simulation}

Once the model has been defined, it is possible to simulate its evolution with time. We use RePast [6] as the underlying simulation engine.

Simulation consists of repeating steps (ticks) until a preset limit is reached or the user clicks on the stop button in the control bar (see Figure 5). For each time step, the following sequence of actions is performed: (1) Provider agents advertise their offers; (2) Both customer and provider agents listen to advertisements; (3) Customer agents try to satisfy their requests: they acquire products based on their buying behaviours; (4) There is a deliberation period for all agents.

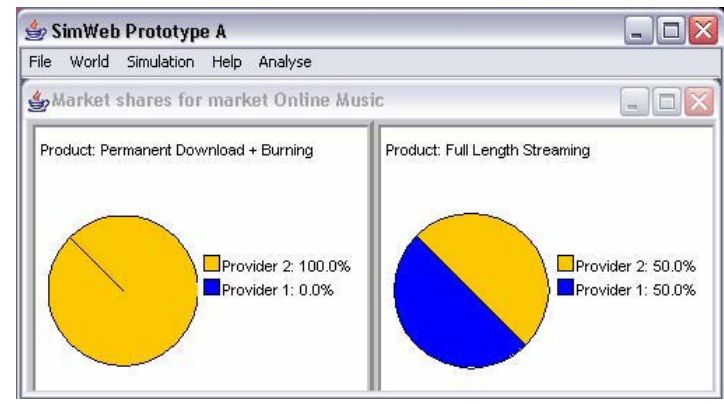

Figure 6. Example of simulation output: market share

Simulation setup allows users to create different scenarios by defining new products, offers and requests, or by changing the number of agents and their behaviours in the music market model (our model has been derived from a close interaction with Fnac.fr, a real on-line music providers). Then, for each step in the simulation, SimwebA refreshes the output graphs in order to show the market evolution. As an example, figure 6 depicts market shares in a given time step for two different music products and two providers. Additionally, sequence graphs are used to display number of sales $\mathrm{x}$ time per provider, and histograms show the range of prices and number of product units that are being sold in the market.

Finally, users can compare the results of different simulations by recording and replying them.

\section{Conclusions and Future Work}

Still in its infancy, organisational simulation is currently a booming area of research in both academia and practice [1]. In this work, we apply the MABS approach because of its intuitive analysis (agents represent stakeholders, act according to their interests and interact within the environment) and flexibility to define different scenarios. In the end, it is the user who decides what attributes the products have and who the providers and customers are.

This paper presents an ongoing work. We are currently working in improving both the market model (adding dynamic behaviours based on rules) and the software tool.

\section{References}

[1] E. Bonabeau, C. and Meyer. 'Swarm Intelligence: A Whole New Way to Think About Business'. Harvard Business Review, Vol. 79, No. 5, pp. 107-114. (2001)

[2] D. Feeny. 'Making Sense of the E-Opportunity'. MIT Sloan Management Review, Vol. 42 n. 2, pp. 41-51, 2001.

[3] C. Krüger, P. Swatman 'Success factors for On-line Music Marketing - eTransformation from the four Ps to the four Cs' Proc. of CollECTeR Latin America. Chile, Sept 2003.

[4] N. Gilbert and K.G. Troitzsch Simulation for the Social Scientist. Milton Keynes: Open University Press, 1999.

[5] L. Godo, R. López de Màntaras. 1993 "Fuzzy Logic.” In Enclycl of Computer Sc \& Technology. Vol 29, 211-229.

[6] RePast : http://repast.sourceforge.net/

[7] A. Reyes, J.A. Rodríguez-Aguilar, M.López-Sánchez, J. Cerquides, D. Gutierrez "Embedding decision support in esourcing tools: Quotes, a case study" Group Decision and Negotiation, vol 12, pp 347-355, Kluwer Ac. (2003)

[8] J. Wooldridge, N. Jennings, and D. Kinny, 'A Methodology for Agent-Oriented Analysis and Design'. In Int. Conf on Autonomous Agents, N.Y. pp. 69-76 (1999).

[9] P. Wurman. 'Dynamic Pricing in the Virtual Marketplace'. IEEE Internet Computing, IEEE CS Vol 5n2, p36-42, 2001

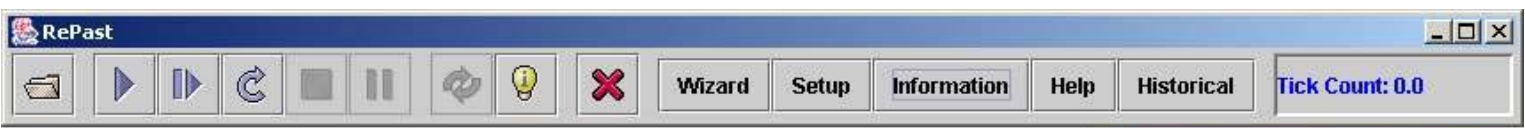

Figure 5. SimwebA simulation toolbar (RePast enhanced): Start, Step, Stop, Wizard for output definition, Agent Information... 